\title{
The Emotional Lexicon and Its Correlates Following Traumatic Brain Injury
}

\author{
Marina Zettin ${ }^{1,2}$, Marzia Leopizzi1 ${ }^{1}$ Domenico Spagnolo1, Valentina Galetto ${ }^{1,2 *}$ \\ ${ }^{1}$ Centro Puzzle, Turin, Italy \\ ${ }^{2}$ Imaging and Plasticity Lab, Department of Psychology, University of Turin, Turin, Italy \\ Email: *valentinagaletto@virgilio.it
}

Received 20 April 2016; accepted 31 May 2016; published 3 June 2016

Copyright (C) 2016 by authors and Scientific Research Publishing Inc.

This work is licensed under the Creative Commons Attribution International License (CC BY). http://creativecommons.org/licenses/by/4.0/

(c) (i) Open Access

\section{Abstract}

Traumatic brain injury (TBI) can often influence the way subjects process and cope with their emotional life. In spite of the huge amount of studies investigating facial emotion recognition in subjects with traumatic brain injury, none of them has examined if their emotional lexicon, i.e. the ability to express emotions through words, may be affected. In this case-control study, we investigated the emotional lexicon of a group of 16 severe TBI subjects, comparing their performances with an healthy control group. A set of 25 visual stimuli (10 single picture images, 5 cartoon story pictures and 10 video clips) were selected. All the stimuli were chosen for their high emotional content by ten blind judges. The participants were asked to describe the stimuli, focusing on their emotional content. To get a better understanding of the correlates of emotional lexicon, all the participants were administered with the backward version of the Digit Span test, the Ekman and Friesen 60 Faces, the 20-Item Toronto Alexithymia Scale and the Empathy Quotient. Results pointed out a significant difference between TBI subjects and healthy controls only for cartoon story and video clip description. Conversely, TBI subjects performed similarly to controls when asked to describe the single picture images. A significant correlation was found in TBI subjects between the results of the Digit Span and number of emotional words, while no correlation was detected between emotional terms and the three scales used to assess TBI subjects' emotional profile. These outcomes highlight that, for more complex stimuli, difficulties in emotional lexicon may depend on factors other than empathy, alexythimia or emotion recognition. These difficulties seem to be related to reduced working memory capacity, which prevent the subjects from correctly processing the emotional content of stimuli.

\section{Keywords}

Traumatic Brain Injury, Emotions, Emotional Lexicon, Working Memory

\footnotetext{
${ }^{*}$ Corresponding author.
}

How to cite this paper: Zettin, M., Leopizzi, M., Spagnolo, D. and Galetto, V. (2016) The Emotional Lexicon and Its Correlates Following Traumatic Brain Injury. Journal of Behavioral and Brain Science, 6, 233-248. 


\section{Introduction}

Traumatic brain injury is one of the main causes of brain damage. Its clinical sequelae result in cognitive and emotional impairments [1] [2] that may significantly compromise the patient's psychosocial and vocational reintegration [3]. If most of the cognitive difficulties tend to recover within the first period, emotional disturbances may impose a great burden on the patient and his (or her) family even in the chronic phase of injury.

Emotional experience is a multicomponential phenomenon [4] [5], including facial expressions, gestures and body movements [6]-[10]. Words are part of this complex construct, as well: the emotional lexicon, i.e. the words or expressions used to describe emotions [11], plays an extremely relevant role in social interactions [12][15], providing human beings with the ability to think about emotional feelings and modulate their emotional states [16]-[19]. Nevertheless, thus far, most of the studies investigating emotional language after traumatic brain injury have principally focused on the assessment of vocal affect recognition, showing that this ability may be compromised in patients with traumatic brain injury [20]-[22].

On the other hand, up to now, no research has tried to solve this issue: may the ability to convey emotions through words be significantly damaged following traumatic brain injury?

As claimed above, the emotional lexicon comprises all the term containing, in their semantic representation, information about a specific emotion or feeling [23]. It can be distinguished from emotional speech in that it only refers to the words conveying emotions, whereas emotional speech also considers prosody [24]-[27].

Clinical evidences coming from the literature and neuroimaging studies have clearly showed that communicating emotion is a complex and multidimensional phenomenon [28]-[30], with different representations in the mental lexicon and a distinct neural network, partially separated from the purely linguistic one [31]. Many studies have pointed out a prevalent recruitment of the right hemisphere in the processing of emotional words [32]-[35]. As early as 1874, John Hughlings Jackson reported that aphasic patients with lesions in the left hemisphere could still convey emotions through words [36], thus indicating the key involvement of the right, unaffected hemisphere for emotional language. This interpretation was further supported by Heilman and colleagues [37], who described a deficit in emotional language production and comprehension following right hemisphere lesions. In the following years, the number of studies highlighting the pivotal engagement of this hemisphere in the emotional language has gradually increased [38]-[40]. At present, however, accumulating evidence suggests that this construct may be processed by a more complex and diffused network, including the cortical and subcortical circuits of both the hemispheres [41]-[43]. A wide set of areas such as temporal lobes, the amygdalae, the basal ganglia and the fronto-parietal as well as frontal and orbito-frontal cortices seem to be recruited in this process [40] [44] [45].

As a consequence of TBI, the more frequently damaged areas typically include the frontal and temporal lobes, with associated diffuse axonal damage [46], resulting from head acceleration, especially rotational [47] [48]. This event might cause the fragmentation and tearing of axons and so trigger an inflammatory process able to affect the connectivity of thousands of neurons, resulting in an impairment of their functional interactions [49]. Thereby, a relatively localized trauma can provide a widespread damage to the brain [50]: the ventrolateral frontal lobes, inferior orbital cortices and temporal lobes are noted to be particularly vulnerable to this kind of injury [51], causing significant cognitive and neurobehavioral sequelae [52]-[54]. Hence, difficulties in emotional processing following TBI might be related to both cortical damage and diffuse axonal injury.

It is well documented in the literature that emotion perception and empathy may be severely compromised in people with traumatic brain injury [20] [51] [55]-[60], with relevant implications in social interactions.

Empathy is an important component of social cognition, comprehending all the operations aimed at detecting other's mental states and future behaviors [61]-[63]. Diminished empathy may result in difficulties in understanding the interlocutor's point of view and identifying the affective value of his (or her) behavior, therefore leading to incongrous reactions.

Many studies have pointed out that reduced empathy may be correlated to higher levels of alexythimia [64] [65] [66]. Similarly to empathy, alexythimia is one of the most common sequelae of TBI [59] [67] [68]. According to Luminet and colleagues [19] it may be due to a limited ability to represent emotions symbolically: in alexithimic subjects there are fewer concepts and images related to emotions [69], with resulting higher difficulties in finding words to communicate feelings.

A further aspects that may significantly interfere with the ability patients have to cope with their emotional life, is the presence of primary cognitive deficits [70] [71]. Among these, working memory difficulties are one 
of the most persistent and disabling consequences of severe traumatic brain injury, significantly interfering with multiple aspects of the patient's recovery: many findings in the literature [72]-[74] point out that these difficulties are negatively correlated to vocational reintegration and psychosocial functioning.

In spite of the huge amount of studies focusing on cognitive and emotional sequelae of TBI, to the best of our knowledge none of them has focused on emotional lexicon and its cognitive and emotional correlates. This lack of studies is surprising, considered that this construct seems to be stricktly related to emotion recognition. According to Balconi and Carrera [75] there is a parallelism between emotion recognition in the visual modalities and their lexical expression: the first emotions to be recognised are also those better verbally described. Verbalisation of emotions is seen as the final step of a process starting with concrete, context-dependent representations and ending with an higher level of abstraction, where the emotional lexicon constitutes "the most convenient non phenomenological access to emotions". Additional proof of the possible connection between emotion recognition and emotional lexicon comes from neuroimaging studies, pointing out a marked overlap between the areas involved in the visual processing of emotions and those implicated in the selection of emotional terms [76]-[79]. In our opinion, a better knowledge of the ability TBI subjects have to use words to describe their and others' emotional states may be of of great importance, since language is one of the most effective way people have to interact and communicate [80].

Following all these premises, we aimed at examining the emotional lexicon of a group of severe TBI subjects. This study has three main purposes: the first one is to assess if emotional lexicon, similarly to facial emotion recognition, is more impaired in TBI participants than in healthy controls, as we hypothesized. The second aim is to examine if there are differences in the amount of emotional words in TBI participants depending on the kind of stimulus used (i.e. static images or dynamic video clips). In fact, many studies in the literature have highlighted that, after TBI, emotion recognition may be differently affected by the utilisation of static or dynamic stimuli [22] [81]-[83]. Results in this field are conflicting: on one hand, dynamic stimuli, that convey more lively and realistic information, are thought to help TBI subjects correctly identifying emotions [22] [81] [83] [84]. On the other hand, emotions' recognition in TBI subjects may be enhanced by the implementation of static and simpler stimuli, that provide the viewer with a significantly higher amount of time to contemplate the stimulus [10] [82]. Based on the latter hypothesis, we expected our TBI participants' emotional lexicon to be similar to that of healthy controls when using simpler stimuli and to be significantly reduced when utilinsing more elaborated stimuli, such as dynamic ones, which require much more information to be processed and integrated.

A further purpose of this study is to understand which are the possible correlates of emotional lexicon in TBI subjects. Our hypothesis is that a reduced emotional lexicon may be influenced by difficulties in recognising facial emotions expressed by other people and by higher levels of alexythimia [15] [67] [85] [86]. Similarly, we expected that a scarse emotional lexicon may also be the consequence of a reduced level of empathy, whose neural correlates, as for alexythimia [87] [88] and emotion recognition [81] [89], partially overlap those of emotional lexicon [90]. An alternative theory may be that there are higher cognitive disturbances, such as working memory ones, which may significantly interferere with the performance of the patients.

The overall idea underlying this study is that a broader knowledge of the nature of emotional difficulties following acquired brain injury may have substantial implications for the clinical practice, helping clinicians in programming rehabilitative interventions tailored on the patients' difficulties and needs [91].

\section{Materials and Methods}

\subsection{Subjects}

Sixteen patients with TBI (10 males and 6 females), recruited in a rehabilitation center for acquired brain injured patients in Turin, were enrolled for participating in this study. The participants' mean age was $38.1(\mathrm{SD}=10.2)$ and their level of education was 11.2 years $(\mathrm{SD}=4)$. All the patients had suffered from severe TBI. Their Glasgow Coma Scale [122], the index used to diagnose the level and the severity of their brain lesions in the acute phase, had to be equal to or less than 8 . The majority of the patients had sustained their injury in a car accident. Their brain lesions mostly involved fronto-parietal and fronto-temporal regions (see Table 1). At the time of the study, all the patients were in the chronic phase of their injury (months after onset, $\mathrm{M}=92.9 ; \mathrm{SD}=65.8$ ). They were living at home, and none of them lived independently without their partners or parents. Their performance was compared to that of 16 healthy controls $(\mathrm{HC})$ (mean age $=38.9$; $\mathrm{SD}=11.4$; mean educational 
Table 1. Brain lesions in TBI subjects.

\begin{tabular}{cccccccc}
\hline TBI subject & Gender & Age & $\begin{array}{c}\text { Months } \\
\text { from TBI }\end{array}$ & $\begin{array}{c}\text { Educational } \\
\text { level }\end{array}$ & Cause of TBI & $\begin{array}{c}\text { Severity } \\
\text { of TBI (GCS) }\end{array}$ & Brain lesion \\
\hline TBI 1 & M & 41 & 216 & 16 & Car accident & 4 & Bilateral fronto-temporal cortex \\
TBI 2 & F & 44 & 133 & 16 & Car accident & 8 & Right fronto-basal cortex \\
TBI 3 & F & 49 & 127 & 8 & Car accident & 5 & Fronto-temporal cortex \\
TBI 4 & F & 47 & 155 & 8 & Car accident & 7 & Corpus callosum and midbrain lesion \\
TBI 5 & M & 56 & 216 & 13 & Car accident & 5 & Fronto-parietal cortex \\
TBI 6 & M & 39 & 96 & 8 & Car accident & 4 & Right fronto-insular and corpus callosum \\
TBI 7 & M & 23 & 68 & 8 & Car accident & 3 & Right midbrain tegmentum \\
TBI 8 & F & 39 & 84 & 8 & Car accident & 3 & Left frontal cortex \\
TBI 9 & M & 29 & 16 & 18 & Car accident & 3 & Bilateral frontal and left temporal cortex \\
TBI 10 & M & 51 & 88 & 8 & Car accident & 5 & Left frontal and temporal cortex \\
TBI 11 & F & 39 & 131 & 18 & Car accident & 4 & Bilateral fronto-parietal cortex \\
TBI 12 & M & 28 & 40 & 13 & Car accident & 5 & Frontal cortex \\
TBI 13 & F & 25 & 20 & 8 & Car accident & 6 & Right parietal cortex \\
TBI 14 & M & 39 & 20 & 8 & Accidental fall & 8 & Left fronto-temporo-parietal cortex lesion \\
TBI 15 & M & 22 & 57 & 8 & Car accident & 6 & Left posterior-parietal cortex injury \\
TBI 16 & M & 38 & 20 & 13 & Car accident & 8 & Right temporo-insular cortex \\
\hline
\end{tabular}

a. This table indicates Traumatic Brain Injured (TBI) participants' clinical and demographic data.

level $=11.2, \mathrm{SD}=3.7$ ). The subject groups did not differ significantly on demographic or basic cognitive variables $\left(\mathrm{t}_{\text {age }}=-0.212, p=0.833 ; \mathrm{t}_{\text {educational level }}=0 p=1\right)$. See Table 2 .

Criteria for including patients in the study were the following. Participants had to: 1) be at least 18 years old; 2) be at least at their 12th month after the brain injury, in order to be sure that their cognitive profile was stable; 3) be Italian native speakers; 4) be in possession of adequate cognitive skills and comprehension abilities, certified by the achievement of a cut-off score of 24/30 on the Mini Mental State Examination (MMSE) [92] and of 29/36 on the Token Test [93]. Exclusion criteria were the following: 1) prior history of TBI or other neurological disease; 2) neuropsychiatric illness; 3) pre-morbid alcohol or drug addiction, evaluated on the basis of the anamnestic data; 4) identified aphasia or agnosia. They gave their written informed consent to participate in the research. Approval for the study had previously been obtained from the local ethics committee.

\subsection{Procedures}

In the first phase of this case-control study, TBI participants were administered with the backward version of the Digit Span test [94], to assess their working memory capacity. Furthermore, they completed a series of scale aimed at exploring their emotional profile: the Ekman and Friesen's Pictures of Facial Affect Series [95], in order to assess their primary emotions' recognition skills; the 20-item Toronto Alexithymia Questionnaire [96] [97] and the Empathy Quotient [63] [98]. During this first phase, participants were supported by a trained psychologist, who intervened in the case of difficulty.

In the second phase of the study, every participant was shown a set of stimuli appearing on a computer screen arranged in front of him (or her) and asked to carefully describe and comment what was happening. The instructions he received were the following: "Look at this picture/video and describe what you see, trying to focus on the emotions you feel while looking at it. Pay also attention to the emotions that, according to you, are felt by the actors". Each stimulus was presented separately. The time allowed for describing the stimuli was not limited. There were three kinds of stimuli. First of all, participants were administered with static stimuli, i.e. ten 
Table 2. Participants' demographic and clinical characteristics.

\begin{tabular}{ccccc}
\hline & Age & Educational level & GCS & Months after onsert \\
\hline TBIs N = 16 & $38.1(10.2)$ & $11.2(4)$ & $5.2(2)$ & $92.9(65.8)$ \\
$\mathrm{HC}=16$ & $38.9(11.4)$ & $11.2(3.7)$ & - & - \\
\hline
\end{tabular}

b. Means (and stardard deviations) of demographic and clinical characteristics of the groups of Traumatic Brain Injured (TBI) and Healthy Control (HC) participants. Asterisk $(*)$ indicates when the group-related difference is significant.

coloured pictures coming from the International Affective Picture System [99] and five cartoon pictures, taken from a popular comic strip (Dylan Dog series). Secondly, they were asked to describe ten short video clips of real movies, chosen for their high emotional content, used as dynamic stimuli. Each video clip lasted 120 seconds. All the video were without audio, so that the subject had to mainly focus on the actors' gestures and expressions.

The order of presentation of the stimuli was counterbalanced between the participants, so as to minimize the impact of order effects. During the picture description task, a free labelling modality was used [75]: participants were asked to freely describe their emotions and the emotions felt by the protagonists of each image/story, without having to complete a forced verbal choice task. In order to avoid poor performance due to short-term memory limitations, the stimuli remained visible until the subject had finished his/her description. Furthermore, to avoid excessive fatigue during the assessment, the administration of the protocol was divided in multiple sessions, each one lasting 45 minutes. All the subjects were audiotaped. Since no normative data are currently available for these tasks, the narratives produced by the TBI group were compared to those uttered by healthy controls.

Each storytelling was subsequently transcribed verbatim by two of the authors.

After transcription, each linguistic sample was analyzed. The scoring procedures were performed independently by two raters and then compared between them. Acceptable inter-rater reliability was defined as $\mathrm{k} \geq 0.80$, and the two raters, after an appropriate training, achieved this level between them prior to the beginning of the study and for all the narrative values of the present study. The residual discrepancies were resolved through discussion.

The analysis consisted in the count of all the words or expressions with an emotional content. In our analysis, we just focused on lexical aspects of emotional language [13], thus ruling out morphological, syntactic and prosodic aspects of discourse. In order to obtain a more objective measure of the number of emotional words, we referred to Zammuner and colleagues' article [5]. In their study, the authors describe an empirically based classification of the Italian emotional lexicon, characterised by 153 emotionally relevant terms. We used this list as starting point for our analysis: in every sample the raters had at first to search for the words inserted in Zammuner and colleagues' list. Then all the linguistic productions were checked for a second time, searching for further terms belonging to the emotional lexicon, but not included in the list. All the terms identified by the raters as "emotionally relevant" were labelled as "emo".

Subsequently, for each linguistic sample we calculated the overall number of emotional words, summing up all the terms labelled as "emo". This value was divided with the total number of words per sample, thus obtaining the relative percentage of emotional words. The same procedure was used for all the linguistic samples. Then, all these indexes were divided in three groups, the first referred to the IAPS images, the second to the cartoon story pictures and the third to the dynamic stimuli. For each group, we calculated descriptive statistics (i.e. means and standard deviations) thus obtaining three indexes: the first referred to the mean relative percentage of emotional words used in the IAPS image description; the second to the mean relative percentage of emotional words used with cartoon story pictures and the third to the mean relative percentage of emotional words elicited by video clip description.

\subsection{Materials}

The severity of traumatic brain injury was diagnosed using the Glasgow Coma Scale [122]. This scale is used to evaluate the patient's clinical evolution during the coma period. It is based on three indexes (ocular, verbal and motor response). Its score ranges between 3 and 15: 3 is referred to a deep state of coma, while 15 indicates the absence of significant loss of consciousness. 
Working memory was investigated using the backward version of the Digit Span task. This is a subtest of the Wechsler Adult Intellingence Scale [94] used to investigate the patient's verbal memory span. In this test the subject is asked to repeat a sequence of numbers from the last digit to the first one. When the string of numbers is correctly repeated, the examiner reads the following one, one digit longer. When the subject fails the first sequence repetition, a second one of the same lenght is administered. The test is stopped when both the sequences are failed.

Facial emotion recognition was investigated using the Ekman and Friesen's Pictures of Facial Affect Series [95]: this test comprises 60 black and white pictures of emotional faces. For every picture, the subject is asked to identify the emotion espressed chosing among six possibilities (i.e., happiness, sadness, surprise, fear, anger or disgust).

To assess alexythimia we used the 20-item Toronto Alexithymia Scale (TAS-20). This self reported questionnaire comprehends 20 items exploring different aspects of alexithymia. It is divided in three subscales, the first related to difficulty identifying feelings, the second to deficits describing emotions and the third to externally oriented thinking. Responses are given on a 5 point Likert scale. The total score can range from 20 to 100. A score $>$ or $=61$ confirms alexithymia; a score between 51 and 60 indicates the presence of possible alexithymia, while a score $<$ or $=51$ suggests the absence of alexithymia. The TAS-20 has demonstrated convergent and discriminant validity, and scores show high agreement with observer ratings of alexithymia [96] [97].

Finally, empathy was explored using the Empathy Quotient, a self reported questionnaire developed to measure the cognitive, behavioral and emotional aspects of empathy. It comprises 60 items exploring empathy and 20 filler items. Responses are given on a four point Likert Scale. A cut off score fewer than 30 is an indication of poor empathy. This scale shows internal consistency, good validity and good test-retest reliability [63] [98] [100].

In the picture description task, patients were administered with 10 pictures taken from the International Affective Picture System [99]. This protocol includes a set of normative coloured pictures for experimental investigations of emotion and attention. Among these, we selected ten images. The pictures were chosen on the basis of their valence and arousal, as rated by ten indipendent blind judges, ranging in age $(\mathrm{M}=30.4 ; \mathrm{SD}=8.3)$ and educational levels $(\mathrm{M}=13.1 ; \mathrm{SD}=5.2)$.

As for the cartoon story description, we used five pictures. These pictures were taken from the Dylan Dog series and were chosen because of their high emotional contents by the same ten raters who selected the IAPS stimuli.

Finally, dynamic stimuli were selected on the basis of a list of 20 video clips taken from famous movies. Each video clip lasted 120 seconds. Once again, the stimuli were chosen because of their high emotional content by the same ten raters who decided the previous stimuli.

\section{Statistical Analysis}

The statistical analysis was carried out with the help of the SPSS software, Version 22.

In order to compare the TBI and the healthy controls' performances on the stimuli description tasks, two-tailed independent $t$-tests were calculated. A p value of 0.05 was chosen as indication of significance.

To understand if the percentage of emotional lexicon varied depending on the task, a One Way Anova with stimuli (IAPS images, cartoon stories and video clips) as indipendent variable and the mean percentage of emotional terms as dipendent variable was calculated.

For the TBI group a series of Pearson correlations were performed between those scales we used to examine the emotional profile of subjects (i.e. The Empathy Quotient; the Toronto Alexythimia Scale and the Ekman and Friesen's Pictures of Facial Affect Series) and the relative percentages of emotionally relevant words.

A further Pearson correlation was calculated between the results of the Digit Span test (backward version) and the percentages of emotional terms produced by TBI patients.

\section{Results}

The outcomes of the backward version of the Digit Span are reported in Table 3, while those of the Empathy Quotient, the 20-Item Toronto Alexythimia Scale and the Friesen's Pictures of Facial Affect Series are reported in Table 4. Finally, the outcomes of the emotional lexicon analysis are reported in Table 5. In cartoon story de- 
Table 3. Digit span (backward version).

\begin{tabular}{ccc}
\hline TBI Subjects & Digit span Backward & Graduated score (Digit Span Test WAIS) \\
\hline TBI 1 & 4 & $6^{*}$ \\
TBI 2 & 4 & $9^{*}$ \\
TBI 3 & 5 & 11 \\
TBI 4 & 2 & $3^{*}$ \\
TBI 5 & 3 & $6^{*}$ \\
TBI 6 & 5 & 10 \\
TBI 7 & 3 & $4^{*}$ \\
TBI 8 & 3 & $6^{*}$ \\
TBI 9 & 3 & $4^{*}$ \\
TBI 10 & 4 & 10 \\
TBI 11 & 2 & $2^{*}$ \\
TBI 12 & 2 & $2^{*}$ \\
TBI 13 & 3 & $7^{*}$ \\
TBI 14 & 3 & $6^{*}$ \\
TBI 15 & 6 & 14 \\
TBI 16 & 5 & 12 \\
\hline
\end{tabular}

c. Results of the Digit span backward for the TBI subjects. The results reported in this table are referred to the maximum length of the sequences every subject was able to repeat backward. Asterisks indicate when the performance is under the cut off for normality (WAIS graduated score $<$ or $=$ 9).

Table 4. TBI participants' emotional profile.

\begin{tabular}{|c|c|c|c|c|}
\hline TBI Subjects & Digit span backward & $\begin{array}{l}\text { Ekman and Friesen's test } \\
\text { (number of errors) }\end{array}$ & Empathy Quotient & Toronto Alexythimia Scale \\
\hline TBI 1 & 4 & 7 & $31^{*}$ & $54^{*}$ \\
\hline TBI 2 & 4 & 12 & $29^{*}$ & $69^{* *}$ \\
\hline TBI 3 & 5 & $16^{*}$ & 34 & $58^{*}$ \\
\hline TBI 4 & 2 & $15^{*}$ & $30^{*}$ & $68^{* *}$ \\
\hline TBI 5 & 3 & $16^{*}$ & $32^{*}$ & $75^{* *}$ \\
\hline TBI 6 & 5 & $25^{*}$ & 40 & $79^{* *}$ \\
\hline TBI 7 & 3 & $17^{*}$ & $32^{*}$ & $56^{*}$ \\
\hline TBI 8 & 3 & $16^{*}$ & $28^{*}$ & 45 \\
\hline TBI 9 & 3 & 7 & 40 & 46 \\
\hline TBI 10 & 4 & $23^{*}$ & $30^{*}$ & $83^{* *}$ \\
\hline TBI 11 & 2 & 10 & $28^{*}$ & 37 \\
\hline TBI 12 & 2 & $21^{*}$ & 35 & $66^{* *}$ \\
\hline TBI 13 & 4 & $15^{*}$ & $28^{*}$ & $75^{* *}$ \\
\hline TBI 14 & 3 & $16^{*}$ & $30^{*}$ & $71^{* *}$ \\
\hline TBI 15 & 6 & $18^{*}$ & 35 & 53 \\
\hline TBI 16 & 5 & 13 & $32^{*}$ & 29 \\
\hline
\end{tabular}


Table 5. Analysis of the emotional lexicon in TBI subjects.

\begin{tabular}{ccc}
\hline Emotional lexicon analysis & TBIs & HC \\
\hline$\%$ emotional lexicon-IAPS stimuli & $4(1.8)$ & $3(1.3)$ \\
$\%$ emotional lexicon- cartoon stories & $1.3(0.4)^{*}$ & $2.7(1.9)$ \\
$\%$ emotional lexicon-videoclips & $2.1(0.6)^{*}$ & $2.9(0.8)$ \\
\hline
\end{tabular}

e. Results of the analysis of the emotional lexicon in the three modalities (IAPS images; cartoon stories and videoclips) for the groups of TBIs and Healthy Controls. Asterisks (*) indicate when the group-related difference is significant.

scription, the HC group produced a higher percentage of emotional words than the TBIs $(\mathrm{t}=-2.79 ; p=0.01)$. The HCs produced a significantly higher quantity of emotional words also in video clip description $(\mathrm{t}=-2.794$; $p=0.009)$. Importantly, the group-related differences were not significant for the IAPS stimuli description $(\mathrm{t}=$ $1.403 ; p=0.171)$. The results of the One Way Anova pointed out a significant effect for the type of stimulus used $(\mathrm{F}=20.39 ; p<0.001)$ only in the TBI group. Post-Hoc comparisons (Tukey Test) highlighted a significant difference between the number of words used to describe the IAPS images and those used to describe cartoon story pictures $(p<0.001)$ and between the number of words produced during the IAPS images description and those elicited during the description of video clips $(p=<0.001)$. Conversely, there was no significant difference between video clips and cartoon story pictures $(p=0.120)$. In healthy controls we found an absence of significant effect among stimuli ( $\mathrm{F}=0.488 ; p=0.617)$. Furthermore, our results failed to show any significant correlation between the three measures used to analyse the emotional profile of TBI participants and the outcomes of the emotional lexicon analysis. The only exception was related to the negative correlation we found between the quantity of emotional words produced with the IAPS stimuli and the number of errors at the Ekman and Friesen's Pictures of Facial Affect Series $(\mathrm{r}=-0.514 ; p=0.042)$. Nevertheless, we found positive correlations between the outcomes of the Digit Span test (backward version) and the percentages of emotional words produced in both cartoon story $(\mathrm{r}=0.535 ; p=0.033)$ and video clip description $(\mathrm{r}=0.856 ; p<0.001)$.

\section{Discussion}

The first purpose of our study was to analyze the features of emotional lexicon in severe TBI subjects. We expected emotional lexicon to be significantly reduced in patients compared to healthy controls. Furthermore, we hypothesized that TBI subjects would find it more difficult to detect and describe emotions in more complex stimuli, such as video clips or cartoon stories. Finally, we wanted to investigate the correlates of emotional lexicon, hypothesizing that it may be influenced by reduced emotion recognition, decreased empathy and higher levels of alexythimia.

The results only partially confirmed our hypothesis. In agreement with our assumptions, we found that TBI participants performed similarly to healthy controls when asked to describe the IAPS images. On the other hand, the two groups significantly differed in the production of emotional words in both video clip and cartoon story picture description. Moreover, our data pointed out a significant effect of the kind of stimulus used to elicit the linguistic production. In particular, post-hoc analyses revealed that the production of emotional terms was higher when patients described static single picture images, like the IAPS ones, while it was reduced in the other tasks. Conversely, no significant effect was found in healthy controls, where the number of emotional terms was similar across tasks. Contrary to what hypothesized, we failed to detect significant correlations between the measures used to assess TBI participants' emotional profile and their emotional lexicon. In fact, although the outcomes of these scales highlighted the presence of reduced empathy, higher levels of alexythimia and impaired facial emotion recognition in almost all the TBI participants, these constructs were not related to the amount of words used to convey emotions. The only exception was related to the negative correlation between the words produced with IAPS images and the outcomes of the Ekman and Friesen's Pictures of Facial Affect Series. In this case we found that the more TBI participants were able to correctly identify facial emotions, the more they used emotional terms when describing pictures.

Taken together, these data suggest that, in the presence of more complex stimuli, such as cartoon story pictures and video clips, TBIs' performance is influenced by factors other than the emotional ones. To this end, we found a positive correlation between working memory capacity and the amount of emotional words produced during more complex tasks. These data are in line with Knox and Douglas' assumption [10]: when the subject is 
asked to describe simpler pictures, with lower amount of information to integrate and more time to contemplate the stimulus, his (or her) emotional lexicon improves. In this case, the performance may partially depend on emotion recognition, because higher cognitive deficits, such as working memory ones, are presumably ruled out [67] [101]. On the contrary, when the complexity of stimuli increases, such as in cartoon story pictures and video clips, TBI subjects may find it more difficult to focus on emotions. The reduced quantity of emotional words, in this case, may be the consequence of a higher cognitive deficit, involving working memory and executive functions. According to the "working memory hypothesis" [102], deficits in the Central Executive System of working memory may be responsible for the broad range of cognitive and behavioral difficulties frequently observed in TBI subjects [103]. Working memory is a limited capacity system used for storing and processing information in cognitive activities. When the demands are greater than the capacity of the system, processing may become slowed down or not completed and the task is compromised [104]. Our data might be interpreted in light of this theory: the increasing amount of information contained in more elaborated stimuli may have slowed down the Central Executive System, with resulting difficulties in focusing on emotions and reduced emotional lexicon. These data are in line with the findings of other studies [10] [20] [82] suggesting that TBI subjects may have significant difficulties recognising the emotions depicted by the actors when they are represented in the dynamic modality instead of the static one.

Data on static and dynamic emotion processing, even if sometimes conflicting, highlight that these two constructs are dissociable and processed by distinct neural networks [105]-[107]. One of the first studies in this field comes from Adolphs and colleagues [76]. The authors described the single case of a man with damage to the inferior temporal and subcortical limbic regions, who had difficulties recognising static emotions, but was able to identify dynamic emotional images. More recent studies [106] [107] have described a broader activation during the processing of emotional dynamic stimuli, including areas such as the fusiform gyrus, dorsolateral prefrontal cortex, middle frontal gyrus and inferior parietal lobule. According to these researches, such a wide neural engagement may be due to the greater visual attention needed to process dynamic stimuli, as opposed to static ones. These data are in line with the hypothesis that the recognition of more elaborated emotional stimuli require higher attentional and working memory load, thus negatively affecting TBIs' performance.

A possible criticism of our theory lies in the hypothesis of Zupan and colleagues [108] who claimed that, when brain injured subjects have access to both vocal and visual aspects of information, they may find it easier to recognise the emotion expressed by the protagonists. Nevertheless, it should be noted that our video clips were presented in a silent modality. Thus TBI participants could not integrate visual and auditory information to increase their knowledge about the actors' emotional state. Even if many studies [20]-[22] have shown that vocal affect recognition may be reduced following TBI, our idea is that, when there is integration between auditory and visual modalities, emotion recognition may be facilitated. On the contrary, in the absence of prosodic cues the elaboration of dynamic visual aspects, constanly changing over time, may be impaired, because of the concomitant working memory deficits.

Another point that deserves discussion is that, although our TBI subjects were regularly attending a neuropsychological rehabilitation program at the time of the study, they still had relevant difficulties coping with more complex emotional stimuli. A possible explanation of these findings lies in the fact that up to now empirical studies have mainly used static displays to assess and treat emotion recognition [107] while, on the contrary, individuals with TBI may require more intervention programs regarding dynamic and naturalistic stimuli, especially when addressing succesful community and work re-entry [83] [108] [109]. Indeed, it could be pertinently argued that the recognition of emotions from photographed faces is far from reflecting real-life situations, in which facial expressions are constantly changing [110]. Instead, dynamic facial emotions provide one with the best representations of people's emotional experience [95] [106]. Furthermore, much more attention should be payed on the analysis of multiple aspects of emotions, including those referring to body gestures and emotional language. In this way, brain injured subjects would be helped to accurately and simultaneously monitor many occurring dynamic cues and to integrate these carefully, to make higher order judgements about speakers' attitude, intentions and opinions [109]. These outcomes could have relevant impact on the subject's quality of life, well contributing to succesful social interactions and work re-integration [91] [111] [112].

The present study had some limitations. The first is referred to the scarceness of the sample, that was only composed by 16 TBI subjects. This aspect may have significantly impacted on the robustness and the significance of our results. Moreover, despite likely frontal involvement, the heterogeneous nature of the brain 
damages of our TBI participants, has impeded the localization of specific structures to the observed emotional deficits. Further replication using a sample with more focal lesions is needed. Another limitation is the use of self-reported measures to assess both empathy and alexythimia. These measures may be vulnerable to influence by a number of variables, including lack of self-awareness and biased perception [20] [59] [91]. However, as the average length of time post-injury was 92.9 months, and insight into difficulties is likely to improve over time [113], the current findings may be considered as valid. Our analysis of the emotional lexicon presents with some drawbacks as well. The first is related to the exclusion of syntatical and prosodic aspects, that, similarly to lexical ones, may have conveyed information about the emotional state of the speaker. The second is that our analysis only considered the total amount of emotional terms: we did not differentiate among words used to describe positive or negative emotions, although many findings in the literature have highlighted that, after TBI, negative emotions are less processed than positive ones [51] [91] [114] [115].

In spite of the limitations, the present study is unique in that it is the first to analyze emotional lexicon following severe TBI, thus highlighting the importance of focusing on aspects of emotion recognition other than those traditionally treated. Further studies are needed to more deeply and specifically analyse emotional language following acquired brain injury. Future prosecutions may use more realistic tasks to elicit the emotional lexicon. Indeed, data from our study pointed out a relatively scarce quantity of emotional terms also in the healthy control group, where the overall emotionally relevant words never exceeded $5 \%$ of the total terms. These outcomes may be the consequence of the task we adopted. Indeed, the use of a description task may have partially contributed to the reduced number of emotional terms used by the participants. On the contrary, by utilising a free production task, where the subject is asked to freely speak about his (or her) personal experience, we would expect an higher amount of emotional words to be elicited [116] [117]. Furthermore, it would be interesting to explore the role of Non Invasive Brain Stimulation and in particular of transcranial Direct Current Stimulation (tDCS), on the modulation on emotional lexicon in brain injured subjects. Previous studies [118] [119] [120] have shown that anodal tDCS on the left dorso-lateral prefrontal cortex may be succesfully used to modify different aspects of healthy subjects' emotional experience, such as ratings of emotional pictures [118] [119] or pain empathy [121]. Future research may focus on the efficacy of this tool in modulating the emotional processing in brain injured subjects, as well.

\section{Conclusion}

The proposed study pointed out significant differences in emotional lexicon between TBI subjects and healthy controls. However, these differences were detected only when using more complex stimuli, while with simpler pictures TBI performed similarly to controls. In our opinion, the reduced emotional lexicon following TBI may be due to higher cognitive difficulties, instead of other emotional disturbances, such as reduced empathy, alexythimia or impaired emotion recognition. These findings may have relevant clinical implications for the rehabilitation of emotional disturbances after traumatic brain injury.

\section{Acknowledgements}

This research has been supported by local research funds managed by Puzzle Rehabilitation Center, Turin. The authors are grateful to the patients who have participated in the research, and to the anonymous reviewers.

\section{References}

[1] Auerbach, S.H. (1986) Neuroanatomical Correlates of Attention and Memory Disorders in Traumatic Brain Injury: An Application of Neurobehavioral Subtypes. The Journal of Head Trauma Rehabilitation, 1, 1-12. http://dx.doi.org/10.1097/00001199-198609000-00004

[2] Filley, C.M. (2010) White Matter: Organization and Functional Relevance. Neuropsychology Review, 20, $158-173$. http://dx.doi.org/10.1007/s11065-010-9127-9

[3] Fontaine, A., Azouvi, P., Remy, P., Bussel, B. and Samson, Y. (1999) Functional Anatomy of Neuropsychological Deficits after Severe Traumatic Brain Injury. Neurology, 53, 1963. http://dx.doi.org/10.1212/WNL.53.9.1963

[4] Scherer, K.R. (1984) Emotion as a Multicomponent Process: A Model and Some Cross-Cultural Data. Review of Personality \& Social Psychology, 5, 37-63.

[5] Zammuner, V.L. (1998) Concepts of Emotion: "Emotionness", and Dimensional Ratings of Italian Emotion Words. 
Cognition \& Emotion, 12, 243-272. http://dx.doi.org/10.1080/026999398379745

[6] Ponsford, J., Willmott, C., Rothwell, A., Cameron, P., Kelly, A.M., Nelms, R. and Ng, K. (2000) Factors Influencing Outcome Following Mild Traumatic Brain Injury in Adults. Journal of the International Neuropsychological Society, 6, 568-579. http://dx.doi.org/10.1017/S1355617700655066

[7] Ponsford, J.L., Olver, J.H. and Curran, C. (1995) A Profile of Outcome: 2 Years after Traumatic Brain Injury. Brain Injury, 9, 1-10. http://dx.doi.org/10.3109/02699059509004565

[8] Douglas, J.M. and Spellacy, F.J. (2000) Correlates of Depression in Adults with Severe Traumatic Brain Injury and Their Carers. Brain Injury, 14, 71-88. http://dx.doi.org/10.1080/026990500120943

[9] Hammond, C. (2004) Impacts of Lifelong Learning upon Emotional Resilience, Psychological and Mental Health: Fieldwork Evidence. Oxford Review of Education, 30, 551-568. http://dx.doi.org/10.1080/0305498042000303008

[10] Knox, L. and Douglas, J. (2009) Long-Term Ability to Interpret Facial Expression after Traumatic Brain Injury and Its Relation to Social Integration. Brain and Cognition, 69, 442-449. http://dx.doi.org/10.1016/j.bandc.2008.09.009

[11] Caldognetto, E.M., Poggi, I., Cosi, P., Cavicchio, F. and Merola, G. (2004) Multimodal Score: An ANVIL ${ }^{\mathrm{TM}}$ Based Annotation Scheme for Multimodal Audio-Video Analysis. Proceedings of the LREC-Workshop on Multimodal Corpora, 25 May 2004, Lisboa, 29-33.

[12] Gawda, B. (2013) The Emotional Lexicon of Individuals Diagnosed with Antisocial Personality Disorder. Journal of Psycholinguistic Research, 42, 571-580. http://dx.doi.org/10.1007/s10936-012-9237-z

[13] Poggi, I. and Magno Caldognetto, E. (2004) Il Parlato Emotivo. Aspetti Cognitivi, Linguistici e Fonetici. Atti del Convegno "Italiano parlato".

[14] van Dijk, T.A. (1997) Discourse as Structure and Process. Vol. 1, SAGE.

[15] Ben-David, B.M., Van Lieshout, P. and Leszcz, T. (2011) A Resource of Validated Affective and Neutral Sentences to Assess Identification of Emotion in Spoken Language after a Brain Injury. Brain Injury, 25, 206-220. http://dx.doi.org/10.3109/02699052.2010.536197

[16] Alford, W.K., Malouff, J.M. and Osland, K.S. (2005) Written Emotional Expression as a Coping Method in Child Protective Services Officers. International Journal of Stress Management, 12, 177-187. http://dx.doi.org/10.1037/1072-5245.12.2.177

[17] Sternberg, R.J. (2005) The Psychology of Hate. American Psychological Association. Washington DC.

[18] Sternberg, R.J. and Weis, K. (2006) The New Psychology of Love. Yale University Press, New Haven.

[19] Luminet, O., Vermeulen, N., Demaret, C., Taylor, G.J. and Bagby, R.M. (2006) Alexithymia and Levels of Processing: Evidence for an Overall Deficit in Remembering Emotion Words. Journal of Research in Personality, 40, 713-733. http://dx.doi.org/10.1016/j.jrp.2005.09.001

[20] McDonald, S. and Saunders, J. (2005) Differential Impairment in Recognition of Emotion across Different Media in People with Severe Traumatic Brain Injury. Journal of the International Neuropsychological Society, 11, 392-399. http://dx.doi.org/10.1017/S1355617705050447

[21] Hornak, J., Rolls, E.T. and Wade, D. (1996) Face and Voice Expression Identification in Patients with Emotional and Behavioural Changes Following Ventral Frontal Lobe Damage. Neuropsychologia, 34, 247-261. http://dx.doi.org/10.1016/0028-3932(95)00106-9

[22] Spell, L. and Frank, E. (2000) Recognition of Nonverbal Communication of Affect Following Traumatic Brain Injury. Journal of Nonverbal Behavior, 24, 285-300. http://dx.doi.org/10.1023/A:1006675230193

[23] Poggi, I., Pelachaud, C. and Caldognetto, E.M. (2003) Gestural Mind Markers in ECAs. In: Camurri, A. and Volpe, G., Eds., Gesture-Based Communication in Human-Computer Interaction, Springer, Berlin Heidelberg, 338-349.

[24] Bachorowski, J.A. and Owren, M.J. (1995) Vocal Expression of Emotion: Acoustic Properties of Speech Are Associated with Emotional Intensity and Context. Psychological Science, 6, 219-224. http://dx.doi.org/10.1111/j.1467-9280.1995.tb00596.x

[25] Ververidis, D. and Kotropoulos, C. (2006) Emotional Speech Recognition: Resources, Features, and Methods. Speech Communication, 48, 1162-1181. http://dx.doi.org/10.1016/j.specom.2006.04.003

[26] Paulmann, S. and Pell, M.D. (2010) Contextual Influences of Emotional Speech Prosody on Face Processing: How Much Is Enough? Cognitive, Affective, \& Behavioral Neuroscience, 10, 230-242. http://dx.doi.org/10.3758/CABN.10.2.230

[27] Barkhuysen, P., Krahmer, E. and Swerts, M. (2010) Crossmodal and Incremental Perception of Audiovisual Cues to Emotional Speech. Language and Speech, 53, 3-30. http://dx.doi.org/10.1177/0023830909348993

[28] Schirmer, A. and Kotz, S.A. (2006) Beyond the Right Hemisphere: Brain Mechanisms Mediating Vocal Emotional Processing. Trends in Cognitive Sciences, 10, 24-30. http://dx.doi.org/10.1016/j.tics.2005.11.009 
[29] Wildgruber, D., Ackermann, H., Kreifelts, B. and Ethofer, T. (2006) Cerebral Processing of Linguistic and Emotional Prosody: fMRI Studies. Progress in Brain Research, 156, 249-268. http://dx.doi.org/10.1016/S0079-6123(06)56013-3

[30] Wildgruber, D., Ethofer, T., Grandjean, D. and Kreifelts, B. (2009) A Cerebral Network Model of Speech Prosody Comprehension. International Journal of Speech-Language Pathology, 11, 277-281. http://dx.doi.org/10.1080/17549500902943043

[31] Pavlenko, A. (2008) Emotion and Emotion-Laden Words in the Bilingual Lexicon. Bilingualism: Language and Cognition, 11, 147-164. http://dx.doi.org/10.1017/S1366728908003283

[32] Ross, E.D. and Mesulam, M.M. (1979) Dominant Language Functions of the Right Hemisphere? Prosody and Emotional Gesturing. Archives of Neurology, 36, 144-148. http://dx.doi.org/10.1001/archneur.1979.00500390062006

[33] Blonder, L.X., Bowers, D. and Heilman, K.M. (1991) The Role of the Right Hemisphere in Emotional Communication. Brain, 114, 1115-1127. http://dx.doi.org/10.1093/brain/114.3.1115

[34] Borod, J.C. (1992) Interhemispheric and Intrahemispheric Control of Emotion: A Focus on Unilateral Brain Damage. Journal of Consulting and Clinical Psychology, 60, 339-348. http://dx.doi.org/10.1037/0022-006x.60.3.339

[35] Kolz, S.A. and Paulmann, S. (2011) Emotion, Language, and the Brain. Language and Linguistics Compass, 5, 108125. http://dx.doi.org/10.1111/j.1749-818X.2010.00267.x

[36] Jackson, J.H. (1874) On the Nature of the Duality of the Brain. The Medical Press and Circular, 1, 41-44.

[37] Heilman, K., Scholes, R. and Watson, R.T. (1975) Auditory Affective Agnosia. Disturbed Comprehension of Affective Speech. Journal of Neurology, Neurosurgery and Psychiatry, 38, 69-72. http://dx.doi.org/10.1136/jnnp.38.1.69

[38] Lalande, S., Braun, C.M.J., Charlebois, N. and Whitaker, H.A. (1992) Effects of Right and Left Hemisphere Cerebrovascular Lesions on Discrimination of Prosodic and Semantic Aspects of Affect in Sentences. Brain and Language, 42, 165-186. http://dx.doi.org/10.1016/0093-934X(92)90123-V

[39] Tabert, M.H., Borod, J.C., Tang, C.Y., Lange, G., Wei, T.C. and Johnson, R. (2001) Differential Amygdala Activation during Emotional Decision and Recognition Memory Tasks Using Unpleasant Words: An fMRI Study. Neuropsychologia, 39, 556-573. http://dx.doi.org/10.1016/S0028-3932(00)00157-3

[40] Wildgruber, D., Riecker, A., Hertrich, I., Erb, M., Grodd, W. and Ethofer, T. (2005) Identification of Emotional Intonation Evaluated by fMRI. NeuroImage, 24, 1233-1241. http://dx.doi.org/10.1016/j.neuroimage.2004.10.034

[41] Wildgruber, D., Hertrich, I., Riecker, A., Erb, M., Anders, S. and Grodd, W. (2004) Distinct Frontal Regions Subserve Evaluation of Linguistic and Emotional Aspects of Speech Intonation. Cerebral Cortex, 14, 1384-1389. http://dx.doi.org/10.1093/cercor/bhh099

[42] Beaucousin, V., Lacheret, A., Turbelin, M.R., Morel, M., Mazoyer, B. and Tzourio-Mazoyer, N. (2007) FMRI Study of Emotional Speech Comprehension. Cerebral Cortex, 17, 339-352. http://dx.doi.org/10.1093/cercor/bhj151

[43] Paulmann, S., Ott, D.V. and Kotz, S.A. (2011) Emotional Speech Perception Unfolding in Time: The Role of the Basal Ganglia. PLoS ONE, 6, e17694. http://dx.doi.org/10.1371/journal.pone.0017694

[44] Ethofer, T., Van de Ville, D., Scherer, K. and Vuilleumier, P. (2009) Decoding of Emotional Information in VoiceSensitive Cortices. Current Biology, 19, 1028-1033. http://dx.doi.org/10.1016/j.cub.2009.04.054

[45] Grandjean, D., Sander, D., Pourtois, G., Schwartz, S., Seghier, M.L., Scherer, K.R. and Vuilleumier, P. (2005) The Voices of Wrath: Brain Responses to Angry Prosody in Meaningless Speech. Nature Neuroscience, 8, 145-146. http://dx.doi.org/10.1038/nn1392

[46] Ietswaart, M., Milders, M., Crawford, J.R., Currie, D. and Scott, C.L. (2008) Longitudinal Aspects of Emotion Recognition in Patients with Traumatic Brain Injury. Neuropsychologia, 46, 148-159. http://dx.doi.org/10.1016/j.neuropsychologia.2007.08.002

[47] Fork, M., Bartels, C., Ebert, A.D., Grubich, C., Synowitz, H. and Wallesch, C.W. (2005) Neuropsychological Sequelae of Diffuse Traumatic Brain Injury. Brain Injury, 19, 101-108. http://dx.doi.org/10.1080/02699050410001726086

[48] Schroeter, M.L. (2012) Considering the Frontomedian Cortex in Revised Criteria for Behavioural Variant Frontotemporal Dementia. Brain, 135, e213. http://dx.doi.org/10.1093/brain/aws030

[49] Smith, D.H., Meaney, D.F. and Shull, W.H. (2003) Diffuse Axonal Injury in Head Trauma. The Journal of Head Trauma Rehabilitation, 18, 307-316. http://dx.doi.org/10.1097/00001199-200307000-00003

[50] Villamar, M.F., Portilla, A.S., Fregni, F. and Zafonte, R. (2012) Noninvasive Brain Stimulation to Modulate Neuroplasticity in Traumatic Brain Injury. Neuromodulation: Technology at the Neural Interface, 15, 326-338. http://dx.doi.org/10.1111/j.1525-1403.2012.00474.x

[51] Croker, V. and McDonald, S. (2005) Recognition of Emotion from Facial Expression Following Traumatic Brain Injury. Brain Injury, 19, 787-799. http://dx.doi.org/10.1080/02699050500110033

[52] Schretlen, D.J. and Shapiro, A.M. (2003) A Quantitative Review of the Effects of Traumatic Brain Injury on Cognitive 
Functioning. International Review of Psychiatry, 15, 341-349. http://dx.doi.org/10.1080/09540260310001606728

[53] Grossi, D. and Trojano, L. (2005) Neuropsicologia dei Lobi Frontali. Sindromi Disesecutive e Disturbi del Comportamento. Il Mulino, Bologna.

[54] Neumann, D., Zupan, B., Malec, J. and Hammond, F. (2014) Relationships between Affect Recognition, Empathy and Alexithymia after Traumatic Brain Injury. The Journal of Head Trauma Rehabilitation, 29, E18-E27. http://dx.doi.org/10.1097/HTR.0b013e31827fb0b5

[55] Babbage, D., Yim, J., Zupan, B., Neumann, D., Tomita, M. and Willer, B. (2011) Meta-Analysis of Facial Affect Recognition Difficulties after Traumatic Brain Injury. Neuropsychology, 25, 277-285. http://dx.doi.org/10.1037/a0021908

[56] Green, R.E., Turner, G.R. and Thompson, W.F. (2004) Deficits in Facial Emotion Perception in Adults with Recent Traumatic Brain Injury. Neuropsychologia, 42, 133-141. http://dx.doi.org/10.1016/j.neuropsychologia.2003.07.005

[57] Shamay-Tsoory, S., Tomer, R., Goldsher, D., Berger, B. and Aharon-Peretz, J. (2004) Impairment in Cognitive and Affective Empathy in Patients with Brain Lesions: Anatomical and Cognitive Correlates. Journal of Clinical and Experimental Neuropsychology, 26, 1113-1127. http://dx.doi.org/10.1080/13803390490515531

[58] Shamay-Tsoory, S., Tomer, R., Berger, B. and Aharon-Peretz, J. (2003) Characterization of Empathy Deficits Following Prefrontal Brain Damage: The Role of the Right Ventromedial Prefrontal Cortex. Journal of Cognitive Neuroscience, 15, 324-337. http://dx.doi.org/10.1162/089892903321593063

[59] Williams, C. and Wood, R. (2010) Alexithymia and Emotional Empathy Following Traumatic Brain Injury. Journal of Clinical and Experimental Neuropsychology, 32, 259-267. http://dx.doi.org/10.1080/13803390902976940

[60] Watts, A.J. and Douglas, J.M. (2006) Interpreting Facial Expression and Communication Competence Following Severe Traumatic Brain Injury. Aphasiology, 20, 707-722. http://dx.doi.org/10.1080/02687030500489953

[61] De Vignemont, F. and Singer, T. (2006) The Empathic Brain: How, When and Why? Trends in Cognitive Sciences, 10, 435-441. http://dx.doi.org/10.1016/j.tics.2006.08.008

[62] Iacoboni, M. (2009) Imitation, Empathy, and Mirror Neurons. Annual Review of Psychology, 60, 653-670. http://dx.doi.org/10.1146/annurev.psych.60.110707.163604

[63] Preti, A., Vellante, M., Baron-Cohen, S., Zucca, G., Petretto, D.R. and Masala, C. (2011) The Empathy Quotient: A Cross-Cultural Comparison of the Italian Version. Cognitive Neuropsychiatry, 16, 50-70. http://dx.doi.org/10.1080/13546801003790982

[64] Moriguchi, Y., Decety, J., Ohnishi, T., Maeda, M., Mori, T., Nemoto, K. and Komaki, G. (2007) Empathy and Judging Other's Pain: An fMRI Study of Alexithymia. Cerebral Cortex, 17, 2223-2234. http://dx.doi.org/10.1093/cercor/bhl130

[65] Gilbert, P., McEwan, K., Gibbons, L., Chotai, S., Duarte, J. and Matos, M. (2012) Fears of Compassion and Happiness in Relation to Alexithymia, Mindfulness, and Self-Criticism. Psychology and Psychotherapy: Theory, Research and Practice, 85, 374-390. http://dx.doi.org/10.1111/j.2044-8341.2011.02046.x

[66] Jonason, P.K. and Krause, L. (2013) The Emotional Deficits Associated with the Dark Triad Traits: Cognitive Empathy, Affective Empathy, and Alexithymia. Personality and Individual Differences, 55, 532-537. http://dx.doi.org/10.1016/j.paid.2013.04.027

[67] Henry, J.D., Phillips, L.H., Crawford, J.R., Ietswaart, M. and Summers, F. (2006) Theory of Mind Following Traumatic Brain Injury: The Role of Emotion Recognition and Executive Dysfunction. Neuropsychologia, 44, 1623-1628. http://dx.doi.org/10.1016/j.neuropsychologia.2006.03.020

[68] Koponen, E., Rantamäki, T., Voikar, V., Saarelainen, T., MacDonald, E. and Castrén, E. (2005) Enhanced BDNF Signaling Is Associated with an Antidepressant-Like Behavioral Response and Changes in Brain Monoamines. Cellular and Molecular Neurobiology, 25, 973-980. http://dx.doi.org/10.1007/s10571-005-8468-Z

[69] Bucci, W. (1997) Psychoanalysis and Cognitive Science: A Multiple Code Theory. The Guilford Press, New York.

[70] Tousignant, B., Jackson, P.L., Massicotte, E., Beauchamp, M.H., Achim, A.M. and Sirois, K. (2016) Impact of Traumatic Brain Injury on Social Cognition in Adolescents and Contribution of Other Higher Order Cognitive Functions. Neuropsychological Rehabilitation, 1-19. http://dx.doi.org/10.1080/09602011.2016.1158114

[71] Martindale, S.L., Morissette, S.B., Kimbrel, N.A., Meyer, E.C., Kruse, M.I. and Dolan, S.L. (2016) Neuropsychological Functioning, Coping, and Quality of Life among Returning War Veterans. Rehabilitation Psychology. http://dx.doi.org/10.1037/rep0000076

[72] McAllister, T.W., Flashman, L.A., McDonald, B.C. and Saykin, A.J. (2006) Mechanisms of Working Memory Dysfunction after Mild and Moderate TBI: Evidence from Functional MRI and Neurogenetics. Journal of neurotrauma, 23, 1450-1467. http://dx.doi.org/10.1089/neu.2006.23.1450

[73] McDowell, S., Whyte, J. and D’Esposito, M. (1997) Working Memory Impairments in Traumatic Brain Injury: 
Evidence from a Dual-Task Paradigm. Neuropsychologia, 35, 1341-1353. http://dx.doi.org/10.1016/S0028-3932(97)00082-1

[74] Iaccarino, M.A., Bhatnagar, S. and Zafonte, R. (2015) Chap. 26. Rehabilitation after Traumatic Brain Injury. In: Grafman, J. and Salazar, A.M., Eds., Handbook of Clinical Neurology, Vol. 127, Elsevier, Amsterdam, 411-422. http://dx.doi.org/10.1016/B978-0-444-52892-6.00026-X

[75] Balconi, M. and Carrera, A. (2005) Il Lessico Emotivo nel Decoding delle Espressioni Facciali. Psychofenia, 8, 17-34.

[76] Adolphs, R., Tranel, D. and Damasio, A.R. (2003) Dissociable Neural Systems for Recognizing Emotions. Brain and Cognition, 52, 61-69. http://dx.doi.org/10.1016/S0278-2626(03)00009-5

[77] Busso, C., Deng, Z., Yildirim, S., Bulut, M., Lee, C.M. and Narayanan, S. (2004) Analysis of Emotion Recognition Using Facial Expressions, Speech and Multimodal Information. Proceedings of the 6th International Conference on Multimodal Interfaces, State College, 13-15 October 2004, 205-211. http://dx.doi.org/10.1145/1027933.1027968

[78] Lee, C.M. and Narayanan, S.S. (2005) Toward Detecting Emotions in Spoken Dialogs. IEEE Transactions on Speech and Audio Processing, 13, 293-303. http://dx.doi.org/10.1109/TSA.2004.838534

[79] Adolphs, R., Damasio, H., Tranel, D., Cooper, G. and Damasio, A.R. (2000) A Role for Somatosensory Cortices in the Visual Recognition of Emotion as Revealed by Three-Dimensional Lesion Mapping. The Journal of Neuroscience, 20, 2683-2690.

[80] Kessous, L., Castellano, G. and Caridakis, G. (2010) Multimodal Emotion Recognition in Speech-Based Interaction Using Facial Expression, Body Gesture and Acoustic Analysis. Journal on Multimodal User Interfaces, 3, 33-48. http://dx.doi.org/10.1007/s12193-009-0025-5

[81] McDonald, S. and Flanagan, S. (2004) Social Perception Deficits after Traumatic Brain Injury: Interaction between Emotion Recognition, Mentalizing Ability, and Social Communication. Neuropsychology, 18, 572-579. http://dx.doi.org/10.1037/0894-4105.18.3.572

[82] Turkstra, L.S., McDonald, S. and De Pompei, R. (2001) Social Information Processing in Adolescents: Data from Normally Developing Adolescents and Preliminary Data from Their Peers with Traumatic Brain Injury. The Journal of Head Trauma Rehabilitation, 16, 469-483. http://dx.doi.org/10.1097/00001199-200110000-00006

[83] Radice-Neumann, D., Zupan, B., Babbage, D.R. and Willer, B. (2007) Overview of Impaired Facial Affect Recognition in Persons with Traumatic Brain Injury. Brain Injury, 21, 807-816. http://dx.doi.org/10.1080/02699050701504281

[84] Wood, R.L., Williams, C. and Kalyani, T. (2009) The Impact of Alexithymia on Somatization After Traumatic Brain Injury. Brain Injury, 23, 649-654. http://dx.doi.org/10.1080/02699050902970786

[85] Larsen, J.K., Brand, N., Bermond, B. and Hijman, R. (2003) Cognitive and Emotional Characteristics of Alexithymia: A Review of Neurobiological Studies. Journal of Psycosomatic Research, 54, 533-541. http://dx.doi.org/10.1016/S0022-3999(02)00466-X

[86] Taylor, G.J., Bagby, R. and Parker, J.D. (2003) The 20-Item Toronto Alexithymia Scale: IV. Reliability and Factorial Validity in Different Languages and Cultures. Journal of Psychosomatic Research, 55, 277-283. http://dx.doi.org/10.1016/S0022-3999(02)00601-3

[87] Meganck, R., Vanheule, S., Inslegers, R. and Desmet, M. (2009) Alexithymia and Interpersonal Problems: A Study of Natural Language Use. Personality and Individual Differences, 47, 990-995. http://dx.doi.org/10.1016/j.paid.2009.08.005

[88] Luminet, O., Rimé, B., Bagby, R.M. and Taylor, G. (2004) A Multimodal Investigation of Emotional Responding in Alexithymia. Cognition and Emotion, 18, 741-766. http://dx.doi.org/10.1080/02699930341000275

[89] Sanchez Cortes, D. (2013). The Influence of Alexithymia and Sex in the Recognition of Emotions from Visual, Auditory, and Bimodalcues. Student Paper, Stockholmsuniversitet.

[90] Lemche, E., Klann-Delius, G., Koch, R. and Joraschky, P. (2004) Mentalizing Language Development in a Longitudinal Attachment Sample: Implications for Alexithymia. Psychotherapy and Psychosomatics, 73, 366-374. http://dx.doi.org/10.1159/000080390

[91] De Sousa, A., McDonald, S., Rushby, J., Li, S., Dimoska, A. and James, C. (2011) Understanding Deficits in Empathy after Traumatic Brain Injury: The Role of Affective Responsivity. Cortex, 47, 526-535. http://dx.doi.org/10.1016/j.cortex.2010.02.004

[92] Tombaugh, T.N. and McIntyre, N.J. (1992) The Mini-Mental State Examination: A Comprehensive Review. Journal of the American Geriatrics Society, 40, 922-935. http://dx.doi.org/10.1111/j.1532-5415.1992.tb01992.x

[93] De Renzi, A. and Vignolo, L.A. (1962) Token Test: A Sensitive Test to Detect Receptive Disturbances in Aphasics. Brain, 85, 665-678. http://dx.doi.org/10.1093/brain/85.4.665

[94] Wechsler, D., Coalson, D.L. and Raiford, S.E. (2008) WAIS-IV: Wechsler Adult Intelligence Scale. Pearson, San 
Antonio.

[95] Ekman, P. and Friesen, W.V. (1976) Measuring Facial Movement. Environmental Psychology and NonVerbal Behavior, 1, 56-75. http://dx.doi.org/10.1007/BF01115465

[96] Bagby, R.M., Parker, J.D. and Taylor, G.J. (1994) The Twenty-Item Toronto Alexithymia Scale-I. Item Selection and Cross-Validation of the Factor Structure. Journal of Psychosomatic Research, 38, 23-32. http://dx.doi.org/10.1016/0022-3999(94)90005-1

[97] Bagby, R.M., Taylor, G.J. and Parker, J.D. (1994) The Twenty-Item Toronto Alexithymia Scale-II. Convergent, Discriminant, and Concurrent Validity. Journal of Psychosomatic Research, 38, 33-40. http://dx.doi.org/10.1016/0022-3999(94)90006-X

[98] Baron-Cohen, S. and Wheelwright, S. (2004) The Empathy Quotient: An Investigation of Adults with Asperger Syndrome or High Functioning Autism, and Normal Sex Differences. Journal of Autism and Developmental Disorders, 34, 163-175. http://dx.doi.org/10.1023/B:JADD.0000022607.19833.00

[99] Lang, P.J., Bradley, M.M. and Cuthbert, B.N. (1997) International Affective Picture System (IAPS): Technical Manual and Affective Ratings. NIMH Center for the Study of Emotion and Attention, Gainesville, 39-58.

[100] Lawrence, E.J., Shaw, P., Baker, D., Baron-Cohen, S. and David, A.S. (2004) Measuring Empathy: Reliability and Validity of the Empathy Quotient. Psychological Medicine, 34, 911-920. http://dx.doi.org/10.1017/S0033291703001624

[101] Umile, E.M., Sandell, M.E., Alavi, A., Terry, C.M. and Plotkin, R.C. (2002) Dynamic Imaging in Mild Traumatic Brain Injury: Support for the Theory of Medial Temporal Vulnerability. Archives of Physical Medicine and Rehabilitation, 83, 1506-1513. http://dx.doi.org/10.1053/apmr.2002.35092

[102] Alderman, N. (1996) Central Executive Deficit and Response to Operant Conditioning Methods. Neuropsychological Rehabilitation, 6, 161-186. http://dx.doi.org/10.1080/713755505

[103] Baddeley, A. and Wilson, B. (1988) Comprehension and Working Memory: A Single Case Neuropsychological Study. Journal of Memory and Language, 27, 479-498. http://dx.doi.org/10.1016/0749-596X(88)90021-6

[104] Moran, C. and Gillon, G. (2005) Inference Comprehension of Adolescents with Traumatic Brain Injury: A Working Memory Hypothesis. Brain Injury, 19, 743-751. http://dx.doi.org/10.1080/02699050500110199

[105] Kilts, C.D., Egan, G., Gideon, D.A., Ely, T.D. and Hoffman, J.M. (2003) Dissociable Neural Pathways Are Involved in the Recognition of Emotion in Static and Dynamic Facial Expressions. NeuroImage, 18, 156-168. http://dx.doi.org/10.1006/nimg.2002.1323

[106] Trautmann, S.A., Fehr, T. and Herrmann, M. (2009) Emotions in Motion: Dynamic Compared to Static Facial Expressions of Disgust and Happiness Reveal More Widespread Emotion-Specific Activations. Brain Research, 1284, 100-115. http://dx.doi.org/10.1016/j.brainres.2009.05.075

[107] Kessler, H., Doyen-Waldecker, C., Hofer, C., Hoffmann, H., Traue, H.C. and Abler, B. (2011) Neural Correlates of the Perception of Dynamic Versus Static Facial Expressions of Emotion. Psycho-Social Medicine, 8, Doc03.

[108] Zupan, B. and Neumann, D. (2014) Affect Recognition in Traumatic Brain Injury: Responses to Unimodal and Multimodal Media. The Journal of Head Trauma Rehabilitation, 29, E1-E12. http://dx.doi.org/10.1097/HTR.0b013e31829dded6

[109] Bornhofen, C. and Mcdonald, S. (2008) Emotion Perception Deficits Following Traumatic Brain Injury: A Review of the Evidence and Rationale for Intervention. Journal of the International Neuropsychological Society, 14, 511-525. http://dx.doi.org/10.1017/S1355617708080703

[110] Pochon, R. and Declercq, C. (2014) Emotional Lexicon Understanding and Emotion Recognition: A Longitudinal Study in Children with Down Syndrome. Journal of Developmental and Physical Disabilities, 26, 549-563. http://dx.doi.org/10.1007/s10882-014-9380-6

[111] Oddy, M. and Herbert, C. (2003) Intervention with Families Following Brain Injury: Evidence-Based Practice. Neuropsychological Rehabilitation, 13, 259-273. http://dx.doi.org/10.1080/09602010244000345

[112] Wood, R.L. and Williams, C. (2008) Inability to Empathize Following Traumatic Brain Injury. Journal of the International Neuropsychological Society, 14, 289-296. http://dx.doi.org/10.1017/S1355617708080326

[113] Long, C. and Ross, L. (1992) Handbook of Head Trauma: Acute Care of Recovery. Plenum Press, New York. http://dx.doi.org/10.1007/978-1-4899-0706-6

[114] Jackson, H.F. and Moffat, N.J. (1987) Impaired Emotional Recognition Following Severe Head Injury. Cortex, 23, 293-300. http://dx.doi.org/10.1016/S0010-9452(87)80039-4

[115] Saunders, J.C., McDonald, S. and Richardson, R. (2006) Loss of Emotional Experience after Traumatic Brain Injury: Findings with the Startle Probe Procedure. Neuropsychology, 20, 224-231. http://dx.doi.org/10.1037/0894-4105.20.2.224 
[116] Douglas-Cowie, E., Campbell, N., Cowie, R. and Roach, P. (2003) Emotional Speech: Towards a New Generation of Databases. Speech Communication, 40, 33-60. http://dx.doi.org/10.1016/S0167-6393(02)00070-5

[117] Niederhoffer, K.G. and Pennebaker, J.W. (2009) Sharing One's Story: On the Benefits of Writing or Talking about Emotional Experience. In: Lopez, S.J. and Snyder, C.R., Eds., Oxford Handbook of Positive Psychology, 2nd Edition, Oxford University Press, New York, 31, 709 p.

[118] Boggio, P.S., Zaghi, S. and Fregni, F. (2009) Modulation of Emotions Associated with Images of Human Pain Using Anodal Transcranial Direct Current Stimulation (tDCS). Neuropsychologia, 47, 212-217. http://dx.doi.org/10.1016/j.neuropsychologia.2008.07.022

[119] Peña-Gómez, C., Vidal-Piñeiro, D., Clemente, I.C., Pascual-Leone, Á. and Bartrés-Faz, D. (2011) Down-Regulation of Negative Emotional Processing by Transcranial Direct Current Stimulation: Effects of Personality Characteristics. PLoS ONE, 6, e22812. http://dx.doi.org/10.1371/journal.pone.0022812

[120] Maeoka, H., Matsuo, A., Hiyamizu, M., Morioka, S. and Ando, H. (2012) Influence of Transcranial Direct Current Stimulation of the Dorsolateral Prefrontal Cortex on Pain Related Emotions: A Study Using Electroencephalographic Power Spectrum Analysis. Neuroscience Letters, 512, 12-16. http://dx.doi.org/10.1016/j.neulet.2012.01.037

[121] Wang, J., Wang, Y., Hu, Z. and Li, X. (2014) Transcranial Direct Current Stimulation of the Dorsolateral Prefrontal Cortex Increased Pain Empathy. Neuroscience, 281, 202-207. http://dx.doi.org/10.1016/j.neuroscience.2014.09.044

[122] Jones, C. (1979) Glasgow Coma Scale. AJN, American Journal of Nursing, 79, 1551-1557. http://dx.doi.org/10.1097/00000446-197909000-00033 